\title{
A Critical Evaluation of the Prothrombin Time for Monitoring Oral Anticoagulant Therapy
}

\author{
Craig M. Jackson ${ }^{a}$ M. Peter Esnouf ${ }^{b}$ Tomas L. Lindahlc \\ aHemoSaga Diagnostics Corp., San Diego, Calif., USA; ' Nuffield Department of Clinical Laboratory Sciences, \\ University of Oxford, Radcliffe Infirmary, Oxford, UK; ' Laboratory Medicine, University Hospital of Linköping, \\ Linköping, Sweden
}

\author{
Key Words \\ International Normalized Ratio - International \\ Standardization Index - Oral anticoagulant therapy • \\ Quick prothrombin time · Thromboplastins • Vitamin K \\ antagonists
}

\begin{abstract}
The Quick prothrombin time is the most common clotting test performed, principally for monitoring oral anticoagulant therapy. The International Normalized Ratio (INR) for comparing patient results from prothrombin time measurements and the International Standardized Index (ISI) for achieving greater consistency of results using different thromboplastins have made it possible to compare the results of vitamin $\mathrm{K}$ antagonist drug therapy that was impossible before the introduction of the INR and ISI. However, INR values obtained from the same patient plasma sample using different thromboplastins are significantly different. This is so even when the thromboplastins have nearly the same ISI values. We suggest that investigation of patient-specific differences can provide a means by which the INR discrepancies can be identified and understood and thus lead to better methods for monitoring oral anticoagulant therapy.
\end{abstract}

\section{Contemporary Monitoring of Oral Anticoagulant Therapy}

Oral anticoagulant therapy is monitored almost universally using the Quick prothrombin time (PT) [1], or one of the variants such as the Owren prothrombin assay $[2,3]$. Monitoring is necessary to balance the risk of thrombosis against the risk of excessive bleeding in the patients receiving vitamin $\mathrm{K}$ antagonists [4]. The currently performed Quick PT is virtually the same as the original assay [1]. Although our knowledge of the pathway by which thromboplastin-initiated coagulation has expanded from an original four components to more than twice that number, our thinking about the sources of variability in PT measurements seen with individual patient samples has not similarly advanced.

The introduction of the International Normalized Ratio (INR) [5-7] provided a substantial improvement to monitoring oral anticoagulant therapy, without which a comparison of results from different laboratories was impossible. The introduction of the International Standardization Index (ISI) enabled the comparison of thromboplastins from different sources. When used with the appropriate formulae [8] these two procedures enabled data from groups of patients in different laboratories and countries to be compared more readily.

\section{KARGER \\ Fax + 41613061234 \\ E-Mail karger@karger.ch \\ www.karger.com

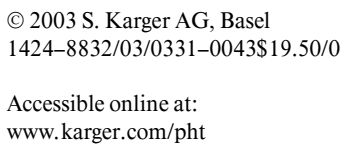

Craig M. Jackson

HemoSaga Diagnostics Corp.

San Diego, CA 92111-1105 (USA)

Tel +1 858505 9914, Fax +1 8585059915

E-Mail cjackso2@san.rr.com 
Fig. 1. a INR values (0.95-1.30) from stable anticoagulated patient's plasma samples measured using four different thromboplastins. $\mathbf{\square}=$ Average INR values; $---=$ the highest and the lowest values obtained for the patient's plasma samples. The numbers shown at the peaks or troughs for some patient INRs indicate which thromboplastins produced the high or low INR values. The ISI values for the thromboplastins varied from 0.707 to 0.863 ; thus all are 'high sensitivity' thromboplastin preparations. Data for a fifth thromboplastin with an ISI of 1.139 are not shown. b INR values (2.4-4.5) from stable anticoagulated patient's plasma samples measured using four different thromboplastins. $\boldsymbol{\square}=$ Average INR values; $---=$ the highest and the lowest values obtained for the patient's plasma samples. The numbers shown at the peaks or troughs for some patient INRs indicate which thromboplastins produced the high or low INR values. The ISI values for the thromboplastins varied from 0.707 to 0.863 ; thus all are 'high sensitivity' thromboplastin preparations. Data for a fifth thromboplastin with an ISI of 1.139 are not shown.
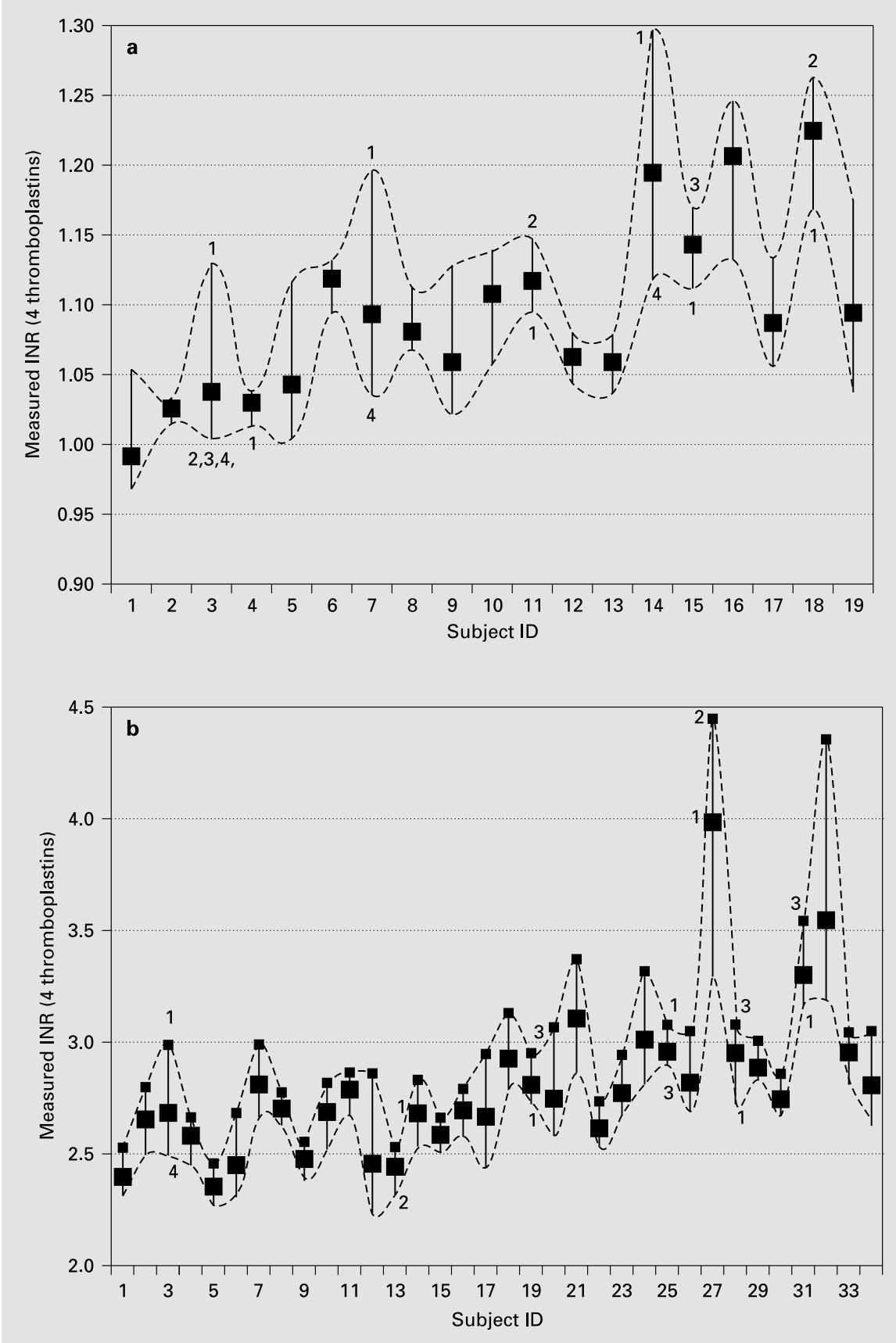

\section{Inconsistency in INR Values for Single Patient Samples Measured with Different Thromboplastins}

Although the INR and ISI have provided methods by which large groups of patients could be compared, however, when individual patient samples are assayed using different thromboplastins, the limitations of this method are evident [9-11]. The most evident limitation is reflected in the fact that the INR values for a single patient sample are significantly different when assayed using different, albeit well-'standardized' thromboplastins. This is illustrated in figure 1a and $b$. Figure 1a shows that INR values for individual patients (subjects) in the 'normal' 
Fig. 2. Relation between INR and ETP. $\bigcirc=$ Individual patients; $\mathbf{O}=$ pooled plasmas of 20 patients at (near) identical INR; line = best-fitting hyperbola. If the ETP is determined in plasmas of anticoagulated patients, the correlation between ETP and INR is significant $(\mathrm{p}<0.005)$ with a correlation coefficient of -0.68 . The therapeutic window of $\mathrm{OAC}$ as measured in the Netherlands [1] is INR 2-4, which corresponds to an ETP of $20-40 \%$.

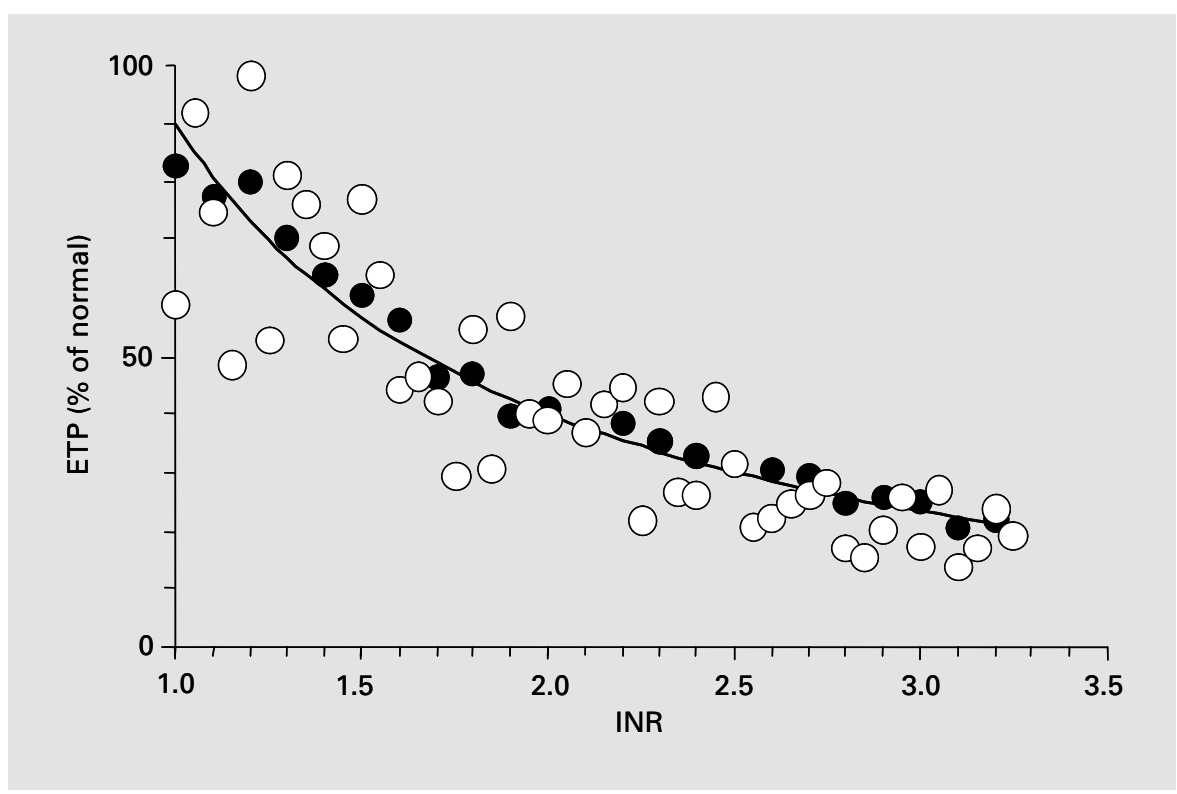

range using different thromboplastins are clearly not the same. Most notable, for some patients the INR values are very consistent with all thromboplastins (except for one lower-sensitivity thromboplastin); in other patients the INR values are clearly different. A closer look shows that for an individual patient, there is little or no relationship between higher or lower INR values and a particular thromboplastin. INR values obtained with thromboplastin A (ISI: 0.831) appear to be higher in more patients than any other single thromboplastin (ISI: 0.707-0.863), but there are patients in which the INR determined with thromboplastin A are lower. Similar patterns are seen in figure $1 \mathrm{~b}$ for patient samples in which the INR is in the therapeutic range for oral anticoagulation. This variability thus does not appear to be related to the ISI value for any particular thromboplastin, but appears to be more likely to reflect differences in components of an individual patient sample.

Although insufficient replicate measurements are available to permit an appropriate statistical estimate to be made, we do not believe that mere experimental variability of clotting times can account for the data of figure 1a and b. Similar data can be found elsewhere, e.g. in manufacturer's comparisons of competitor thromboplastin preparations that can be found on the Internet. An explanation that cannot be ignored is that the ISI procedure for 'standardizing' thromboplastins, in spite of its success, does not succeed completely in normalizing the differences on the level of the individual patient sample and thus alternative methods for monitoring vitamin $\mathrm{K}$ antagonist therapy must be investigated. An examination of any graph that is used to determine the ISI value for a particular thromboplastin, in spite of the logarithmic transformation of the data, shows substantial scatter among the points around the line from which the ISI is calculated. This observation similarly argues that the source of the variability is to be found in the samples from the patients. Therefore, the evaluation of these individual samples may be the most straightforward way to identify the factors responsible for this variability that is otherwise attributed to differences in the thromboplastins employed.

The measurement of the endogenous thrombin potential (ETP), described elsewhere in this volume, shows a reasonably good correlation with the INR (be it not a linear one) when pooled plasma of patients with approximately the same degree of anticoagulation are compared, but with individual samples the correlation is much weaker (fig. 2). The ETP values are however independent of the thromboplastin used and also independent of the thromboplastin concentration (if $>1 \%$ of the concentration used in PT measurements [Hemker, pers. commun.]). However, in figure 2 because the INR is used as the parameter against which the ETP is plotted, variability is evident in this graph as well. Only an independent evaluation of the relationship between the ETP and the 'state of anticoagulation' will enable the ETP to be shown to be 'free' of the variability that is characteristic of INR values. 


\section{Prothrombin Time - Components and Reactions}

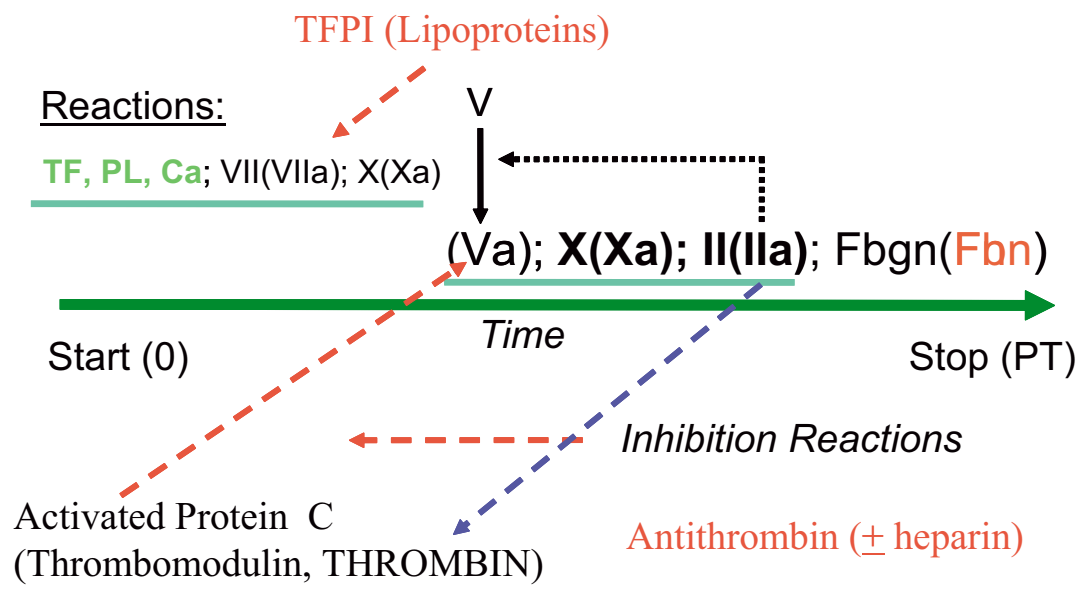

tions and components that are involved in the PT assay. TF $=$ Tissue factor; $\mathrm{PL}=$ phospholipids; Fbgn $=$ fibrinogen; Fbn $=$ fibrin .

\section{Properties of Thromboplastins That Can Affect the PT Assay}

The reactions that lead to thrombin formation in the PT assay begin with binding of factor (F) VII to the tissue factor molecules of the thromboplastin and the conversion of FVII to FVIIa (fig. 3). FVII and FVIIa also bind to the phospholipids in the thromboplastin, although the specificity of interaction is determined by the FVII-tissue factor complex [12-16]. The most commonly used thromboplastins are extracts derived from tissue homogenates of rabbit brain or human placenta. Newer thromboplastins may be formulated from recombinant tissue factor and synthetic phospholipids. However, the recombinant products from different manufacturers are not identical [17-19]. The PT assay is started when thromboplastin and calcium chloride are added to the citrated patient plasma sample. The thromboplastin is the only reagent over which manufacturers can exercise control; the remaining components in the processes that lead to thrombin formation are provided by the patient sample.

Clearly tissue factor molecules in thromboplastins derived from different animal species, including recombinant tissue factor, are unlikely to behave identically [20, 21]. Both the affinities and the changes in the FVII that result from its binding to different tissue factor molecules undoubtedly contribute to the differences that are observed. For example rabbit tissue factor is ineffective in the activation of a mutant human FVII, whereas recombi- nant human tissue factor is effective [21]. The interactions are also altered by the changes in the FVII molecules and the other vitamin-K-dependent proteins that are modified during the action of the oral anticoagulant drug.

Our current knowledge of the interactions between proteins and lipid membranes [22-27] suggests many possible reasons for the variability between individual thromboplastins. The components and properties of the thromboplastins that are relevant to the interaction with FVII and FX on the surface of the phospholipid of the thromboplastin include: the degree of dispersion of the thromboplastin (multi-lamellar, single-lamellar); phospholipid surface available; phospholipid composition of the thromboplastin (relative ratios of phosphatidylserine, phosphatidylethanolamine and phosphatidylcholine) [28] and surface concentration of the tissue factor on the exposed bilayer surface.

Surface concentration of tissue factor and the total phospholipid surface determines how many FVII molecules can be bound to the thromboplastin. Although one FVII molecule binds to one tissue factor molecule, the actual rate of FX that is converted to FXa (fig. 3) is related to the total number of tissue factor molecules available. Because FVII also interacts directly with phospholipid molecules, the phospholipid composition of the thromboplastin can change the affinity of the tissue factor in the bilayer for FVII, FVIIa and FX. Affinity is also affected by the physical state and mobility of the phospholipid 
Fig. 4. Extent of anticoagulation measured for a single patient over a 2.5 -month period using three different assay methods that are sensitive to the extent of $\gamma$-carboxylation of the Gla domain residues in the vitamin-Kdependent proteins.

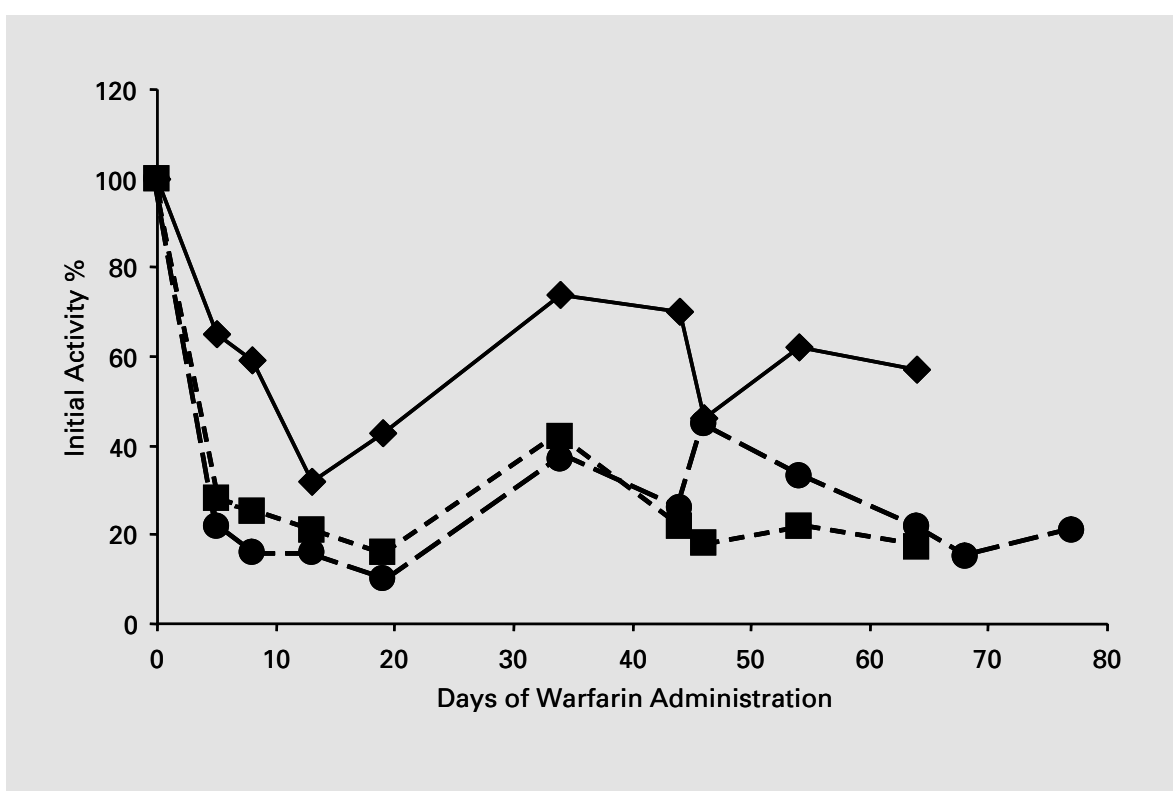

molecules [29]. Thromboplastins prepared from recombinant tissue factor and synthetic phospholipids are almost entirely made of single bilayer lipid vesicles with maximum exposure of tissue factor, however, the thromboplastins prepared from brain and placenta are unlikely to be so.

\section{Molecular Differences between Vitamin-K- Dependent Proteins in Normal Subjects and in Patients Receiving Vitamin K Antagonist Drugs}

The vitamin-K-dependent proteins in plasma of individuals who are not being given oral anticoagulants are fully functional molecules that possess 10-12 Gla residues, i.e. glutamic acid residues (Glu) with an additional carboxyl group at the $\gamma$ carbon [30-33]. Gla residues are formed posttranslationally in the liver in a vitamin-Kdependent process that is inhibited by oral anticoagulants [30]. Incompletely carboxylated proteins do not bind calcium in the same way as the normal molecules [34, 35] and therefore do not undergo the conformation change that is required for binding to the phospholipid surface [36-38]. More detailed descriptions of the action of the vitamin $\mathrm{K}$ antagonists and their effects on the structures and functionality of the proteins are found in the literature [30, 39-44].

The prothrombin time is a general measure of the rates of activation of all of the components that participate in the reactions, beginning with tissue factor binding of FVII/FVIIa and ending with fibrin clot formation (fig. 3). Rates of activation of the proteins in this sequence depend on their binding to the phospholipid surface. The affinities of the under-carboxylated molecules are negligible compared to the fully carboxylated species [45]. The consequence of this is the slowing of the processes and the lengthening of the clotting time, although the thrombin that is formed is normal.

Generation of thrombin requires the conversion of three proteinase precursors into their proteolytically active forms: FVII to FVIIa, FX to FXa and prothrombin to thrombin (fig. 4). The most rapid activation of these precursors occurs in their respective complexes with their cofactor proteins: tissue factor for FVII to FVIIa and FX to $\mathrm{FXa}$ and $\mathrm{FV}$ a for prothrombin to thrombin. Although tissue factor is fully functional upon exposure, FV must be converted to its reactive form before it can participate [46]. The mechanism by which FV is converted to its reactive form is achieved by thrombin, possibly also by Xa. Both these proteins are vitamin $\mathrm{K}$ dependent and thus the rate of activation of $\mathrm{FV}$ is also influenced by oral anticoagulant therapy, because both the concentrations and rates of formation of these $\mathrm{FV}$ activators are decreased. Consequently, vitamin $\mathrm{K}$ antagonist drugs both directly and indirectly affect thrombin generation. Apart from the availability of vitamin $\mathrm{K}$, various other processes govern the normal synthesis of individual vitamin-K-dependent proteins [47]. 
Fig. 5. Influence of anti-vitamin $\mathrm{K}$ treatment on the thrombomodulin sensitivity of the ETP thrombogram. In each set of two thrombin generation curves the lower one is obtained in the presence of $10 \mathrm{n} M$ soluble recombinant thrombomodulin [from Hemker et al., this issue, pp. 4-15].

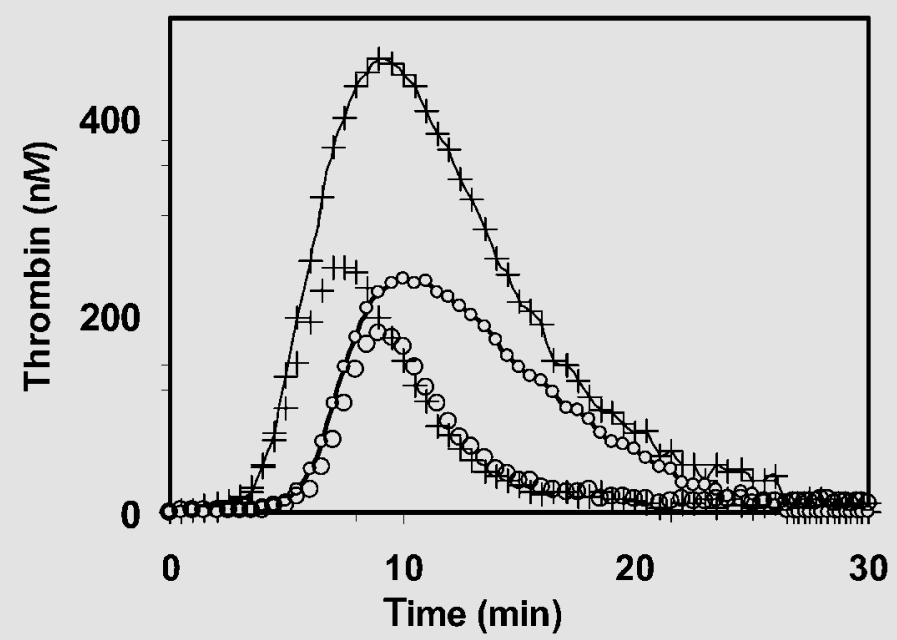

thromboplastin, and thus exhibiting longer clotting times and a sensitivity to 'lupus anticoagulants', suggest that the short clotting times characteristic of conventional PT measurements have effectively masked this source of variability.

When the PT assay was conceived, many of the currently known clotting factors were unknown. Perhaps most importantly, tissue factor pathway inhibitor (TFPI) [53-55], thrombomodulin and proteins $\mathrm{C}$ and $\mathrm{S}$, which are vitamin $\mathrm{K}$ dependent, had not been discovered. These components, along with antithrombin and other inhibitors oppose the formation of thrombin [56, 57]. TFPI is a potent inhibitor of FVIIa and FXa when they are associated with tissue factor $[54,58,59]$, thus its role as a regulator of the reactions involved in the PT assay merits further investigation. Thrombomodulin is assumed to have little influence on the INR [60], but the experimental basis for this assumption is limited.

The rationale for in vitro measurement of $\mathrm{PT}$ is that it is assumed suitable for assessing the hemostatic state of the patient in vivo. The discovery of the many important regulatory reactions that are mentioned above, and to which the PT appears to be insensitive, calls this assumed relationship between in vivo and in vitro into question. Especially because the influence of protein $\mathrm{C}$ activation on the hemostatic mechanism in vivo is important, as can be judged for example from the prothrombotic effect of the FV Leiden mutation, the assumption must be qualified, at least, or perhaps even abandoned. 
It is interesting to note that the effect of thrombomodulin on the clotting system can be readily measured via thrombin generation (fig. 5). Although the effect of oral anticoagulants on protein $\mathrm{C}$ is considered to be less than on the other vitamin-K-dependent proteins [61], the presence of the des Gla forms of protein $\mathrm{C}$ apparently result in 'thrombomodulin resistance' as well as the reduction of thrombin generation.

One additional consideration deserves mention, namely the endpoint of PT, as is true for all clotting time measurements, is the gelation of fibrin to form the clot. Thus in monitoring anticoagulant therapy by PT, the influence of the fibrinogen concentration should not be ignored [62] also because thrombin inactivation is reduced through thrombin binding to fibrin [63], additional fibrin-related interactions also likely to be involved in patients with elevated fibrinogen concentrations.

\section{Conclusions and Recommendations}

It is important to recall that all assays that use clotting times as endpoints of a series of reactions provide only composite measures of elapsed time and do not provide clear information about individual reactions. In the interval between initiation of clotting and the formation of the fibrin gel, opposing reactions, e.g. activation of proteinase precursors and $\mathrm{FV}$, are countered by inactivation of the proteinases by antithrombin and TFPI and inactivation of activated $\mathrm{FV}$ by activated protein $\mathrm{C}[64,65]$. Thus, like travel from one city to another in a fixed period of time, several paths are possible, several different delays but all with a fixed result that contains no information about the path or the cause of delays. This limitation is frequently unrecognized or unacknowledged in PT measurements with the consequence that apparently satisfactory INR values may hide information that, if it were available, might warn clinicians of impending bleeding or thrombotic risks. It is also worth recalling that all interpretations are based on the components known at the time. The discovery of protein $\mathrm{C}$, thrombomodulin, TFPI and the possible involvement of protein $\mathrm{Z}$ [66-68] in some of the reactions of coagulation must remind us that interpretations are likely to be changed as new components and reactions are recognized.

In large groups of patients ( 3,000 patient years), there is an excellent statistical correlation between the INR and thrombosis on the one hand and bleeding on the other [60]. The value of the INR and the ISI enabling comparison of different laboratory results cannot be un- dervalued. However, a correlation does not necessarily imply a causal relationship, and an appropriate therapeutic intervention is more likely when the cause that provokes a need for a therapeutic intervention is correctly identified. It is clear that the PT in the individual patient shows so much thromboplastin-dependent variation that one might be led to think that each thromboplastin measures different quantitative contributions to the tissuefactor-initiated clotting process. Such a situation is clearly less than ideal for making clinical decisions.

Similarly, all thromboplastins, at the concentrations they are used in the PT assay, appear to be insensitive to most of the regulatory reactions of the hemostatic process. These regulatory reactions and components (antithrombin, the protein $\mathrm{C}$ system) certainly influence the occurrence of thrombosis and bleeding in patients and thus test(s) that are sensitive to them are needed for screening patients for risk of hemorrhage or thrombosis.

Discovery of new clotting factors, particularly those present in trace amounts in plasma and the reactions of the hemostatic system in which they are involved, has been possible because of the observations in the clinic on patients whose hemorrhagic predisposition could not be explained by the clotting factors known at the time. If only because of the historical value, it is recommended here that the differences in results from individual patients with different thromboplastin reagents be the focus for identifying the underlying cause(s) and thus developing better tests for monitoring vitamin $\mathrm{K}$ antagonist drug therapy in individual patients.

The essential question of what test, if any, accurately reflects the bleeding or thrombotic tendency of a patient remains at this moment unanswered. Thrombin generation is a very promising candidate because it has been shown to be sensitive to more phases of the blood clotting process than our existing tests. It is to be hoped that the ETP will provide more valuable information on the hemostatic status of the patient than the currently available tests. 


\section{References}

1 Quick AJ: The prothrombin time in hemophilia and in obstructive jaundice. J Biol Chem 1935;109:73-74.

2 Owren PA, Aas K: The control of Dicumarol therapy and quantitative determination of prothrombin and proconvertin. Scand J Clin Lab Invest 1951;3:201-208.

3 Owren P: Thrombotest. A new method for controlling anticoagulant therapy. Lancet 1959; ii:754-758.

4 Gallus AS, Hirsh J: Antithrombotic drugs: Part I. Drugs 1976;12:41-68.

5 Lewis SM: ICSH/ICTH recommendations for reporting prothrombin time in oral anticoagulant control. J Clin Pathol 1985;38:133-134.

6 Loeliger EA, Van Den Besselaar AM, Lewis SM: Reliability and clinical impact of the normalization of the prothrombin times in oral anticoagulant control. Thromb Haemost 1985; 53:148-154.

7 Lewis SM: Standardization of the laboratory control of oral anticoagulant therapy. Blood 1983;61:210.

8 WHO Expert Committee on Biological Standardization. World Health Organ Tech Rep Ser 1999;889:i-vi, 1-111, i-111.

9 Testa S, Morstabilini G, Fattorini A, Galli L, Denti N, D'Angelo A: Discrepant sensitivity of thromboplastin reagents to clotting factor levels explored by the prothrombin time in patients on stable oral anticoagulant treatment: Impact on the international normalized ratio system. Haematologica 2002;87:1265-1273.

10 Lind SE, Pearce LA, Feinberg WM, Bovill EG: Clinically significant differences in the International Normalized Ratio measured with reagents of different sensitivities. SPAF Investigators. Stroke Prevention in Atrial Fibrillation. Blood Coagul Fibrinolysis 1999; 10:215-227.

11 Hillarp A, Egberg N, Fagerberg I, Lindahl TL, Nordin G, Stigendal L: Less variation in laboratory results after the introduction of INR. Differences between hospital laboratories and laboratories within primary health care are levelled out (in Swedish). Lakartidningen 2002; 99:5068-5074.

12 Banner DW, D'Arcy A, Chene C, Winkler FK, Guha A, Konigsberg WH, Nemerson Y, Kirchhofer D: The crystal structure of the complex of blood coagulation factor VIIa with soluble tissue factor (see comments). Nature 1996;380: 41-46.

13 Contino PB, Andree HA, Nemerson Y: Flow dependence of factor $\mathrm{X}$ activation by tissue factor-factor VIIa. J Physiol Pharmacol 1994;45: 81-90.

14 Contino PB, Hasselbacher CA, Ross JB, Nemerson $\mathrm{Y}$ : Use of an oriented transmembrane protein to probe the assembly of a supported phospholipid bilayer. Biophys J 1994;67:11131116.

15 Kirchhofer D, Nemerson Y: Initiation of blood coagulation: The tissue factor/factor VIIa complex. Curr Opin Biotechnol 1996;7:386-391.
16 Harlos K, Martin DM, O'Brien DP, Jones EY, Stuart DI, Polikarpov I, Miller A, Tuddenham EG, Boys CW: Crystal structure of the extracellular region of human tissue factor. Nature 1994;370:662-666.

17 Bray JE, Malan E, Gan TE, Peverill RE: Clinical significance of international normalised ratio (INR) variability with the use of different thromboplastins (abstract). Cardiac Society of Australia and New Zealand, 2001.

18 Renier JL, Baufine-Ducrocq H, Samama MM: Variability of INR due to thromboplastin. Comparison of two recombinant thromboplastins and one rabbit thromboplastin (in French). Ann Biol Clin (Paris) 1995;53:353-356.

19 Brummel KE, Paradis SG, Branda RF, Mann KG: Oral anticoagulation thresholds. Circulation 2001;104:2311-2317.

20 Bader R, Mannucci PM, Tripodi A, Hirsh J, Keller F, Solleder EM, Hawkins P, Peng M, Pelzer H, Teijidor LM, et al: Multicentric evaluation of a new PT reagent based on recombinant human tissue factor and synthetic phospholipids. Thromb Haemost 1994;71:292299.

21 O'Brien DP, Gale KM, Anderson JS, McVey JH, Miller GJ, Meade TW, Tuddenham EG: Purification and characterization of factor VII 304-Gln: A variant molecule with reduced activity isolated from a clinically unaffected male. Blood 1991;78:132-140.

22 Mimms LT, Zampighi G, Nozaki Y, Tanford C, Reynolds JA: Phospholipid vesicle formation and transmembrane protein incorporation using octyl glucoside. Biochemistry 1981;20: 833-840.

23 Smith R, Tanford C: The critical micelle concentration of L- $\alpha$-dipalmitoylphosphatidylcholine in water and water-methanol solutions. J Mol Biol 1972;67:75-83.

24 Tanford C: Thermodynamics of micelle formation: Prediction of micelle size and size distribution. Proc Natl Acad Sci USA 1974;71: 1811-1815.

25 Tanford C: The Hydrophobic Effect: Formation of Micelles and Biological Membranes. New York, Wiley-Interscience, 1980, pp 1233.

26 Tanford C: Micelle shape and size. J Phys Chem 1972;76:3021-3024.

27 Ueno M, Tanford C, Reynolds JA: Phospholipid vesicle formation using nonionic detergents with low monomer solubility. Kinetic factors determine vesicle size and permeability. Biochemistry 1984;23:3070-3076.

28 Smirnov MD, Ford DA, Esmon CT, Esmon NL: The effect of membrane composition on the hemostatic balance. Biochemistry 1999;38: 3591-3598.

29 Tans G, Van Zutphen H, Comfurius P, Hemker HC, Zwaal RFA: Lipid phase transitions and procoagulant activity. Eur J Biochem 1979;95:449-457.

30 Suttie JW: Mechanism of action of vitamin K: Synthesis of $\gamma$-carboxyglutamic acid. CRC Crit Rev Biochem 1980;8:191-223.
31 Esnouf MP, Prowse CV: The gamma-carboxy glutamic acid content of human and bovine prothrombin following warfarin treatment. Biochim Biophys Acta 1977;490:471-476.

32 Lindhout M, Kop-Klaassen B, Hemker HC: The effect of gamma-carboxyglutamate residues on the enzymatic properties of the activated blood clotting factor X: I. Activity towards synthetic substrates. Biochim Biophys Acta 1978;533:342-354.

33 Malhotra OP: Atypical prothrombins induced by dicoumarol. Nat New Biol 1972;239:5960.

34 Stenflo J, Ganrot P: Binding of $\mathrm{Ca}^{2+}$ to normal and dicoumarol-induced prothrombin. Biochem Biophys Res Commun 1972;50:98-104.

35 Nelsestuen GL: Role of gamma-carboxyglutamic acid. An unusual protein transition required for the calcium-dependent binding of prothrombin to phospholipid. J Biol Chem 1976;251:5648-5656.

36 Friedman PA, Rosenberg RD, Hauschka PV, Fitz-James A: A spectrum of partially carboxylated prothrombins in the plasmas of coumarin-treated patients. Biochim Biophys Acta 1977;494:271-276.

37 Bjork I, Stenflo J: A conformational study of normal and dicoumarol-induced prothrombin. FEBS Lett 1973;32:343-346.

38 Welsch DJ, Nelsestuen GL: Amino-terminal alanine functions in a calcium-specific process essential for membrane binding by prothrombin fragment 1. Biochemistry 1988;27:49394945.

39 Esmon CT, Suttie JW, Jackson CM: The functional significance of vitamin $\mathrm{K}$ action. Difference in phospholipid binding between normal and abnormal prothrombin. J Biol Chem 1975; 250:4095-4099.

40 Jackson CM, Suttie JW: Recent developments in understanding the mechanism of vitamin $\mathrm{K}$ and vitamin $\mathrm{K}$-antagonist drug action and the consequences of vitamin $\mathrm{K}$ action in blood coagulation; in Brown EC (ed): Progress in Hematology. New York, Grune \& Stratton, 1977, vol X, pp 333-359.

41 Nelsestuen GL, Suttie JW: Mode of action of vitamin $\mathrm{K}$ calcium binding: Properties of bovine prothrombin. Biochemistry 1972;11: 4961-4964.

42 Stenflo J, Suttie JW: Vitamin K-dependent formation of $\gamma$-carboxyglutamic acid. Annu Rev Biochem 1977;46:157-172.

43 Suttie JW: Oral anticoagulant therapy: The biosynthetic basis. Semin Hematol 1977;14:365374.

44 Suttie JW: Vitamin K-dependent carboxylation. Trends Biochem Sci 1980;5:302-304.

45 Esmon CT, Suttie JW, Jackson CM: The functional significance of vitamin $\mathrm{K}$ action. Difference in phospholipid binding between normal and abnormal prothrombin. J Biol Chem 1975; 250:4095-4099. 
46 Esmon CT, Owen WG, Duiguid D, Jackson CM: The action of thrombin on blood clotting factor V: Conversion of factor V to a prothrombin-binding protein. Biochim Biophys Acta 1973;310:289-294.

47 Erhardtsen E, Nony P, Dechavanne M, Ffrench P, Boissel JP, Hedner U: The effect of recombinant factor VIIa (NovoSeven) in healthy volunteers receiving acenocoumarol to an International Normalized Ratio above 2.0. Blood Coagul Fibrinolysis 1998;9:741-748.

48 Shetty HG, Woods F, Routledge PA: The pharmacology of oral anticoagulants: Implications for therapy. J Heart Valve Dis 1993;2:53-62.

49 Vigano'D'Angelo S, Gugliotta L, Mattioli BM, Cascione ML, Pattarini E, D'Angelo A: Lasparaginase treatment reduces the anticoagulant potential of the protein $\mathrm{C}$ system without affecting vitamin K-dependent carboxylation. Thromb Res 1990;59:985-994.

50 Bezeaud A, Drouet L, Leverger G, Griffin JH, Guillin MC: Effect of L-asparaginase therapy for acute lymphoblastic leukemia on plasma vitamin K-dependent coagulation factors and inhibitors. J Pediatr 1986;108:698-701.

51 Prowse C: The effects of oral anticoagulants on the synthesis of glycoproteins; thesis, Oxford University, 1976.

52 Nesheim ME, Canfield WM, Kisiel W, Mann KG: Studies of the capacity of factor Xa to protect factor $\mathrm{Va}$ from inactivation by activated protein C. J Biol Chem 1982;257:1443-1447.
53 Broze GJ Jr: Tissue factor pathway inhibitor and the revised hypothesis of blood coagulation. Trends Cardiovasc Med 1992;2:72-77.

54 Broze GJ Jr, Girard TJ, Novotny WF: Regulation of coagulation by a multivalent Kunitztype inhibitor. Biochemistry 1990;29:75397546.

55 Rapaport SI: The extrinsic pathway inhibitor: A regulator of tissue factor-dependent blood coagulation. Thromb Haemost 1991;66:6-15.

56 Bjork I, Olson ST, Shore JD: Molecular mechanisms of the accelerating effect of heparin on the reactions between antithrombin and clotting proteinases; in Lane DA, Lindahl U (eds): Heparin, Chemical and Biological Properties, Clinical Applications. Boca Raton, CRC Press, 1989, pp 229-256.

57 Olson ST, Bjork I, Shore JD: Kinetic characterization of heparin-catalyzed and uncatalyzed inhibition of blood coagulation proteinases by antithrombin. Methods Enzymol 1993;222: 525-559.

58 Nordfang O, Kristensen HI, Valentin S, Ostergaard $\mathrm{P}$, Wadt $\mathrm{J}$ : The significance of TFPI in clotting assays - Comparison and combination with other anticoagulants. Thromb Haemost 1993;70:448-453.

59 Ofosu FA: Anticoagulant actions of tissue factor pathway inhibitor on tissue-factor-dependent plasma coagulation. Semin Thromb Hemost 1995;21:240-244.

60 Azar AJ, Cannegieter SC, Briet JW, vanBergen $\mathrm{E}$, Jonker JJ, Rosendaal FR: Optimal intensity of oral anticoagulant therapy after myocardial infarction. J Am Coll Cardiol 1996;27:13491355.
61 Simmelink MJ, de Groot PG, Derksen RH, Fernandez JA, Griffin JH: Oral anticoagulation reduces activated protein $\mathrm{C}$ less than protein $\mathrm{C}$ and other vitamin K-dependent clotting factors. Blood 2002;100:4232-4233.

62 Chitolie A, Mackie IJMSJ: The type of thrombopolastin reagent has important effects on the PT-derived fibrinogen potency. Lab Hematol 1998;4:149-155.

63 Hogg PJ, Jackson CM: Heparin promotes the binding of thrombin to fibrin polymer: Quantitative characterization of a thrombin-fibrin polymer-heparin ternary complex. J Biol Chem 1990;265:241-247.

64 D’Angelo SV, Comp PC, Esmon CT, D’Angelo A: Relationship between protein $\mathrm{C}$ antigen and anticoagulant activity during oral anticoagulation and in selected disease states. J Clin Invest 1986;77:416-425.

65 Esmon CT: Brief review: Protein-C: Biochemistry, physiology and clinical implications. Blood 1983;52:1155-1158.

66 Hogg PJ, Stenflo J: Interaction of vitamin Kdependent protein $\mathrm{Z}$ with thrombin. Consequences for the amidolytic activity of thrombin and the interaction of thrombin with phospholipid vesicles. J Biol Chem 1991;266:1095310958.

67 Prowse C, Esnouf MP: The isolation of a new warfarin-sensitive protein from bovine plasma. Biochem Soc Trans 1977;5:255-256.

68 Broze GJ Jr, Miletich JP: Human protein Z. J Clin Invest 1984;73:933-938. 